Published in final edited form as:

Am J Kidney Dis. 2017 September ; 70(3): 422-439. doi:10.1053/j.ajkd.2017.01.055.

\title{
Management of Gout and Hyperuricemia in CKD
}

\author{
Ana Beatriz Vargas-Santos, MD and \\ Universidade do Estado do Rio de Janeiro, Boulevard Vinte e Oito de Setembro, 77, sala 333, \\ Rheumatology, Rio de Janeiro, RJ 20551-030, Brazil; phone +55 21 2868-8216, fax +55 21 \\ 2334-2433 \\ Tuhina Neogi, MD, PhD, FRCPC \\ Boston University School of Medicine, 650 Albany Street, Suite X-200, Clinical Epidemiology \\ Research and Training Unit, Boston, MA 02118, USA; phone 617-638-5180, fax 617-638-5239
}

\begin{abstract}
Hyperuricemia and gout, the clinical manifestation of monosodium urate crystal deposition, are common in patients with chronic kidney disease (CKD). While the presence of CKD poses additional challenges in gout management, effective urate-lowering is possible for most patients with CKD. Initial doses of urate-lowering therapy are lower than in the non-CKD population, while incremental dose escalation is guided by regular monitoring of serum urate to reach the target of less than $6 \mathrm{mg} / \mathrm{dL}$ (or less than $5 \mathrm{mg} / \mathrm{dL}$ for patients with tophi). Management of gout flares with presently available agents can be more challenging due to potential nephrotoxicity and/or contraindications in the setting of other common comorbidities. At present, asymptomatic hyperuricemia is not an indication for urate-lowering therapy, though emerging data may support a potential renoprotective effect.
\end{abstract}

\section{INDEX WORDS}

Hyperuricemia; gout; chronic kidney disease; urate-lowering therapy; allopurinol; febuxostat; uricosurics; uricase; colchicine; nonsteroidal anti-inflammatory drugs; glucocorticoids; management; review.; Supplemented with renal failure; hemodialysis; kidney transplant; chronic gout; acute gout; gout flare; therapy; treatment

\section{CASE PRESENTATION}

A 58-year old man with long-standing non-tophaceous gout presents to the emergency room with incapacitating pain due to arthritis in the left knee and right first metatarsophalangeal (MTP) joint. He has chronic kidney disease (CKD), currently stage 3b (estimated glomerular filtration rate (eGFR) of $32 \mathrm{~mL} / \mathrm{min}$ ). His most recent serum urate (SUA) level is $7.9 \mathrm{mg} / \mathrm{dL}$.

Corresponding author: Associate Professor Tuhina Neogi, Boston University School of Medicine, 650 Albany Street, Suite X-200, Clinical Epidemiology Research and Training Unit, Boston, MA 02118, USA; phone 617-638-5180, fax 617-638-5239; tneogi@bu.edu.

Publisher's Disclaimer: This is a PDF file of an unedited manuscript that has been accepted for publication. As a service to our customers we are providing this early version of the manuscript. The manuscript will undergo copyediting, typesetting, and review of the resulting proof before it is published in its final citable form. Please note that during the production process errors may be discovered which could affect the content, and all legal disclaimers that apply to the journal pertain. 
He is currently taking allopurinol $100 \mathrm{mg} /$ day, a dose that was based on his creatinine clearance $(\mathrm{CrCl})$. He also has hypertension, dyslipidemia, and congestive heart failure. $\mathrm{He}$ avoids non-steroidal anti-inflammatory drugs (NSAIDs) and limits his colchicine prophylactic dose to one tablet every other day due to his kidney disease. He has also been told by his cardiologist to avoid prednisone due to possible fluid overload with resultant decompensation of his congestive heart failure (CHF). This is his third visit to the emergency room within the last year due to gout-related pain.

\section{INTRODUCTION}

Gout, the clinical manifestation of crystalline monosodium urate (MSU) deposition, is the most common inflammatory arthritis in adults, especially in men, with increasing prevalence worldwide, ranging from 0.1 to $10 \%$ and estimated to be $3.9 \%$ in the US. ${ }^{1,2}$ Hyperuricemia, which is biochemically defined as SUA $\succ 6.8 \mathrm{mg} / \mathrm{dL}$ based on the limit of urate solubility, is even more common. Using population level sex-specific SUA distributions to define hyperuricemia, a US study reported a prevalence of $21.2 \%$ among men (SUA $>7.0 \mathrm{mg} / \mathrm{dL}$ ) and $21.6 \%$ among women $(\mathrm{SUA}>5.7 \mathrm{mg} / \mathrm{dL})^{2}$

As two-thirds of human urate excretion occurs through the kidneys, with the remaining onethird occurring through the gastrointestinal tract, decreased kidney function is associated with hyperuricemia. On the other hand, several large epidemiologic studies and small trials suggest that hyperuricemia may potentially be associated with the development and progression of hypertension and CKD. ${ }^{3}$ Regardless of which is cause or consequence, the association of CKD with gout and hyperuricemia is common. ${ }^{4,5}$ Approximately $20 \%$ of adults with gout have CKD stage $\geq 3$ compared with $5 \%$ of individuals without gout; $15 \%$ of adults with hyperuricemia have CKD stage $>3$ compared with $3 \%$ of individuals without hyperuricemia. ${ }^{6}$ The age-standardized prevalence of gout and hyperuricemia increases as kidney function declines, with $24 \%$ of adults with eGFR $<60 \mathrm{~mL} / \mathrm{min}$ having gout compared with $2.9 \%$ of adults with eGFR $\geq 90 \mathrm{~mL} / \mathrm{min}^{5}$

Clinicians are frequently confronted, therefore, with managing gout in the setting of kidney disease. The management of gout flares can be challenging because of cautions or contraindications in those with diminished kidney function as well as other common comorbidities that occur frequently in CKD. Among adults with CKD stage 3, 87.8\% have hypertension, $16.9 \%$ have diabetes, $22.9 \%$ have ischemic heart disease, and $3.5 \%$ have CHF. ${ }^{7}$ Similarly, patients with gout, irrespective of kidney disease, have high prevalence of these conditions. ${ }^{6}$ These comorbidities impact therapeutic decision making, particularly for gout flare management since the agents available have precautions and/or contraindications in these settings. On the other hand, there is often unnecessary excessive concern regarding urate-lowering therapy (ULT) in the context of CKD, frequently leading to inadequate management of gout.

\section{CLINICAL CONTEXT}

The most typical presentation of gout is the acute onset of a monoarthritis, generally affecting the lower limbs (classically the $1^{\text {st }}$ MTP joint), lasting 7-14 days without therapy, 
followed by an asymptomatic period of varying duration. ${ }^{8}$ Without treatment, flares tend to recur progressively more frequently, last for longer periods and can become more resistant to treatment for some. In later stages, a chronic inflammatory arthritis can occur with persistent symptoms; often tophi develop with longer duration of disease, although occasionally tophi can be the initial clinical manifestation of gout. ${ }^{9}$ In women, the first presentation of gout generally occurs after menopause because of the uricosuric effects of estrogen. ${ }^{10}$ While mono- or oligoarthritis of a lower limb is a common gout flare presentation, other patterns are not infrequent, such as upper limb involvement and polyarticular flares. ${ }^{11}$ Patients with CKD are anecdotally thought to have more variable presentations of their gout flares, including higher frequency of polyarticular flares. These presentations are also more common among women and elderly individuals, and often are associated with diuretic use and CKD. ${ }^{12-14}$ Thus, clinicians must remember to consider gout flare in their differential diagnosis of acute joint complaints in a patient with kidney disease, even if the pattern of joint involvement is not "classic".

The diagnosis of gout is confirmed by the identification of MSU crystals under polarizing microscopy in synovial fluid aspirated from a joint or bursa or in material aspirated from a tophus. This gold-standard confirmation is especially important for patients with CKD, among whom the prevalence of other conditions that mimic gout is also common, such as calcium pyrophosphate (CPP) deposition disease (formerly known as "pseudogout", and now labelled acute CPP crystal arthritis), for which the diagnosis is also confirmed by synovial fluid analysis. ${ }^{15}$

In the absence of a crystal-proven diagnosis, other elements of the history and physical exam can be helpful in supporting a diagnosis of gout. While not intended for use in making diagnoses, the 2015 American College of Rheumatology (ACR) - European League Against Rheumatism classification criteria for gout highlight some of the key factors to consider when evaluating an individual for the possibility of gout. ${ }^{16,17}$ Classification criteria are intended for use in research to identify individuals for enrollment into clinical studies, and therefore do not necessarily cover the full spectrum of the disease.

\section{MANAGEMENT OF GOUT IN CKD}

The management of gout follows the same four principles regardless of the presence of CKD: 1) lower SUA (i.e., manage the hyperuricemia); 2) provide prophylaxis while initiating ULT; 3) treat gout flares; and 4) optimize dietary and lifestyle factors as appropriate. Over a prolonged period of time with adequate management of hyperuricemia, defined as maintenance of a SUA level $<6 \mathrm{mg} / \mathrm{dL}$ or $<5 \mathrm{mg} / \mathrm{dL}$ for those with tophaceous gout, gout flares will diminish in frequency and severity, with eventual cessation of flares, and tophi can be prevented and/or resolve.

\section{Management of Hyperuricemia}

Hyperuricemia is a necessary, though not sufficient, cause of gout since there are many more individuals with hyperuricemia than with clinically evident gout. Nonetheless, the mainstay and primary focus of gout therapy is to lower elevated SUA to achieve the clinical outcomes 
that matter to patients: cessation and prevention of flares, resolution and prevention of tophi, and control of inflammatory arthritis for those with chronic gouty arthritis.

In 2012, the ACR published guidelines for the management of gout. ${ }^{18,19}$ New in these guidelines was the recommendation to initiate ULT with the first flare of gout in patients with CKD stage 2 and worse. ${ }^{18}$ The rationale for this new ULT indication is that these patients often have limited options for gout flare management. By initiating ULT earlier, the aim is to avoid the need to treat subsequent gout flares with potentially nephrotoxic or contraindicated agents. For patients with normal eGFR, indications for ULT continue to include recurrent gout flares ( $\geq 2$ per year), tophi, and nephrolithiasis. In addition imaging evidence of tophi is a new indication for ULT.

In line with other treatment guidelines, the ACR guidelines noted insufficient evidence to address management of asymptomatic hyperuricemia. ${ }^{18,20-22}$ As reviewed below, there are emerging data regarding potential benefit of ULT in CKD beyond the context of gout that points to the need for large trials to definitively address this issue.

Non-pharmacological approaches can be recommended to all gout patients as adjunctive measures; these include weight loss and avoiding excess intake of purine-rich foods, alcoholic beverages and fructose-rich beverages. Total prohibition of purine intake is not recommended since the impact on SUA is limited (reduction of approximately $1 \mathrm{mg} / \mathrm{dL}$ ) and this represents a great burden for the patient; thus lifestyle approaches should be considered adjunctive and should not replace pharmacologic treatment. ${ }^{23}$ Further, since the primary determinant of hyperuricemia in most patients is related to kidney clearance of uric acid, either reflecting inherited kidney transport factors and/or low eGFR, blaming the patient for their gout is counterproductive and contributes to poor management of gout as patients are reluctant to discuss their condition with health care providers. ${ }^{24,25}$

Pharmacological therapy for lowering SUA includes uricosuric agents that address the most common cause of hyperuricemia, kidney urate underexcretion, xanthine oxidase inhibitors that prevent purine metabolites from being converted to UA, and uricase therapy that oxidizes UA through an enzymatic reaction that is no longer present in humans to the highly soluble end-product, allantoin (Table 1). At lower GFR levels, uricosuric agents may not be efficacious; accordingly agents with other mechanisms of action need to be used. While dialysis in principle is uricosuric and is often accompanied by a reduction in gout flares despite persistent hyperuricemia, dialysis patients may still require ULT to achieve the SUA target and tophus resolution. ${ }^{26,27}$ There are other mechanisms also being targeted, though none are advanced enough in their development for approval or clinical use.

Regardless of which ULT is chosen, general principles include: initiation of therapy concomitantly with prophylaxis; use of a low starting dose followed by regular monitoring of the SUA level with ongoing dose titration until the target is achieved; ULT should not be withdrawn or have its dose changed during gout flares; and SUA should continue to be monitored with additional dose adjustments as needed (Box 1). Optimally, ULT should be initiated when the patient is free of a gout flare, although the 2012 ACR gout treatment guidelines propose that ULT could be started during a gout flare as long as effective anti- 
inflammatory therapy has been established. However, this approach has not been fully tested for potential negative consequences, such as prolonging a flare, and can add to a patient's confusion about which medication is being used for which purpose. ${ }^{38,39}$

\section{Box 1}

\section{General approach to managing hyperuricemia in gout patients}

Initiate anti-inflammatory prophylaxis concomitantly with or before starting uratelowering therapy

Start urate-lowering therapy at a low dose and titrate dose to serum urate target

Check serum urate regularly

Aim for a serum urate target level of $<6 \mathrm{mg} / \mathrm{dL}$ for most patients; consider $<5 \mathrm{mg} / \mathrm{dL}$ for some, such as those with tophi

Maintain anti-inflammatory prophylaxis for at least 6 months, continuing until after both serum urate target achievement and resolution of clinical manifestations (last flare, tophus resorption)

Xanthine oxidase inhibitors (XOI)-Xanthine oxidase converts purine metabolites to UA. Thus, XOIs decrease the production of UA from endogenous and dietary purine sources and are considered first-line therapy, though uricosurics are an acceptable alternate first-line option. ${ }^{18}$

Allopurinol-Allopurinol, a purine base analogue available since the 1960's, is the most widely used ULT. Although it is effective, its appropriate use has been hampered by certain misconceptions. This is largely due to the decades-old proposed allopurinol dose adjustment according to $\mathrm{CrCl}$ to levels that should theoretically achieve the same serum level of oxypurinol, the active metabolite, as a $300 \mathrm{mg}$-dose of allopurinol would achieve in a patient with normal kidney function. ${ }^{40}$ This algorithm was developed to theoretically mitigate against the risk for allopurinol hypersensitivity syndrome (AHS), which manifests as rash, eosinophilia, leukocytosis, fever, hepatitis and progressive kidney failure, with high mortality rates. ${ }^{40}$ However, this strategy has never been proven to lower this risk in patients who tolerate low starting doses of allopurinol. ${ }^{28}$ Further, with this dosing strategy, fewer than $50 \%$ of patients achieve the target SUA level. ${ }^{18,41-44}$ Notably, the peak dose of allopurinol does not appear to be associated with AHS in patients with CKD; rather the risk of AHS is primarily related to the initial dose of allopurinol and whether the patient is a carrier of the variant HLA-B*5801 allele, and the risk is highest in the first 6 months of use. $^{45-51}$

The dose of allopurinol can be safely increased beyond the CrCl-based dose in patients with kidney disease; allopurinol can be used in patients receiving hemodialysis or peritoneal dialysis who still require ULT, as detailed in Table $1 .{ }^{45,52-55}$ For all patients initiating allopurinol, the starting dose should be low, specifically $50 \mathrm{mg} /$ day for patients with CKD stage 4 or 5 , and no more than $100 \mathrm{mg} /$ day in all others. ${ }^{18}$ Initiating ULT at a low dose aims 
to reduce the risk of gout flare and of AHS or other allergic reactions. The daily dose should then be up-titrated by 50 to $100 \mathrm{mg}$ every $2-5$ weeks as needed to achieve the SUA target. ${ }^{18}$

Febuxostat-Febuxostat is a non-purine selective XOI that was FDA-approved in 2009. Trials assessing febuxostat's efficacy compared it with a fixed dose of allopurinol of 300 $\mathrm{mg} / \mathrm{day}$, or $200 \mathrm{mg} / \mathrm{day}$ in those with some degree of kidney disease. ${ }^{56-59}$ Since this dose of allopurinol is not sufficient to adequately achieve the SUA target for a majority of patients, it is not clear from these trials how superior febuxostat is in comparison with appropriately titrated allopurinol; a randomized controlled trial is currently underway to assess this. Febuxostat can be used in patients with eGFR $230 \mathrm{~mL} / \mathrm{min}$ without dose adjustment. However, the data on efficacy and safety of febuxostat in CKD stages $\geq 3$, including kidney replacement therapy, are limited. In the CONFIRMS trial, which randomized 2269 participants, only $18 \%$ had an estimated $\mathrm{CrCl}$ below $60 \mathrm{~mL} / \mathrm{min}$, while one of the largest trials of XOIs to date in people with CKD stage 3 and 4 only randomized 96 participants. ${ }^{59,60}$ Most other trials included only subjects with CKD stage 2 or better. There are only some case reports, small clinical trials, and observational studies on use of febuxostat in patients on dialysis and/or with kidney transplant. ${ }^{30-34,61,62}$

Regarding side effects, the frequency of mild skin reactions was similar to those in allopurinol treatment arms in these trials, at $2-5 \% .56,57,59$ Some severe cases of adverse cutaneous reactions have been reported, including drug reaction with eosinophilia and systemic symptoms (DRESS) syndrome, Stevens-Johnson syndrome and toxic epidermal necrolysis, particularly in patients with history of cutaneous adverse reactions to allopurinol and in patients with CKD, leading to a warning by the European Medicines Agency (EMA) and Health Canada regarding this issue ${ }^{63-67}$ No association between HLA-B*5801 allele status and these reactions has been reported to date. There was a potential cardiovascular safety signal in the initial febuxostat trials program, with additional trials required prior to approval. ${ }^{68}$ In the postmarketing period, there have been some reported cases of heart failure leading Health Canada to request the manufacturer to include a warning for the risk of heart failure in patients with cardiovascular disease and/or other risk factors in the Canadian label ${ }^{69}$ Studies comparing the safety of febuxostat and allopurinol are currently underway. ${ }^{70,71}$

The cost-effectiveness of febuxostat has been evaluated in comparison with allopurinol. However, interpretation of these studies is challenging as some were sponsored by the manufacturer of febuxostat and most used suboptimal doses of allopurinol as the comparator arm. ${ }^{72-75}$ The ACR guidelines does not distinguish between the two XOI since cost was not considered; allopurinol may therefore be a reasonable initial option for most patients. ${ }^{76}$

Uricosurics-Uricosuric agents act through transporter proteins involved in kidney urate reabsorption and/or secretion, such as UA transporter 1 (URAT1), glucose transporter 9 (GLUT9), organic anion transporter 1 (OAT1), OAT3, OAT4 and OAT10.

Uricosurics are underused, particularly in the US. This is partly related to the need for multiple tablets and twice daily dosing of probenecid, which, until recently, was the only uricosuric agent available in the US. Lesinurad, a uricosuric URAT-1 and OAT-4 inhibitor 
approved by the FDA in 2015, must be co-prescribed with a XOI, because, in randomized trials, lesinurad monotherapy was associated with acute kidney failure more commonly than the comparator arms; thus an indication for monotherapy was not pursued. Creatinine rises noted during these trials were generally reversible. Benzbromarone is a more potent uricosuric drug but is not FDA-approved in the US and unavailable in some European countries due to concerns regarding hepatotoxicity. ${ }^{77}$

Uricosurics must be avoided in patients with prior nephrolithiasis and are contraindicated in the presence of uricosuria higher than $700-800 \mathrm{mg} / 24$ hours. Patients on a uricosuric agent must assure adequate fluid intake due to risk of nephrolithiasis. Because uricosurics lose efficacy as kidney function declines, probenecid is not recommended for those with $\mathrm{CrCl}$ $<30 \mathrm{~mL} / \mathrm{min}$, and lesinurad is not recommended for those with $\mathrm{CrCl}<45 \mathrm{~mL} / \mathrm{min}$.

While not developed as drugs that reduce urate, two commonly used drugs have uricosuric properties: losartan and fenofibrate. Losartan, an angiotensin receptor blocker, is commonly used in all stages of CKD. The safety of fenofibrate is uncertain in advanced kidney disease, particularly in combination with statins due to increased risk of rhabdomyolysis.

Uricase-Pegloticase is a pegylated recombinant porcine uricase, the enzyme responsible for converting UA to allantoin, which is more soluble than uric acid and therefore more easily eliminated. Its approved use is for gout that is refractory to oral ULT. Pegloticase is administered intravenously every two weeks, with the current label supporting 6 months of therapy, though longer term therapy has been successfully reported. Following completion of that regimen, patients are transitioned back to oral ULT. Because pegloticase is derived from porcine uricase and is pegylated, there is a risk for immunogenicity, with infusion reactions and anaphylaxis. The reported rate of hypersensitivity reactions was $26 \%$ and $44 \%$ for infusions every 2 weeks and monthly, respectively, in a 6-month study, and $44 \%$ in an openlabel extension study (18\% were severe reactions). ${ }^{78,79}$ Anaphylaxis occurred in $\sim 5 \%$ of subjects in the pivotal trials that led to approval. ${ }^{78}$ Hypersensitivity reactions are highly correlated with rising SUA levels; thus SUA must be assessed prior to each infusion and therapy must be discontinued if SUA is $>6 \mathrm{mg} / \mathrm{dL}$ on two successive occasions. Pegloticase, which is administered with $250 \mathrm{~mL}$ of normal saline, can be used in advanced CKD, including in dialysis patients, without dose adjustment. ${ }^{35}$ Reports of heart failure associated with pegloticase have prompted a label warning, advising exercising caution in patients who have congestive heart failure and monitoring patients closely following infusion.

\section{Anti-Inflammatory Prophylaxis of Gout Flares}

Colchicine and NSAIDs are considered first-line drugs for prophylaxis of gout flares, and less preferably low-dose glucocorticoids may also be considered when colchicine and NSAIDs are contraindicated (Table 2). ${ }^{19}$ Current guidelines recommend prescribing prophylaxis for all patients initiating ULT and maintaining prophylaxis for as long as there is evidence of ongoing gout disease activity (i.e., flare or tophus) and/or the SUA target has not been achieved. In particular, prophylaxis should be continued for the greater of: at least six months, three months beyond reaching the SUA target for those without tophi, or six months 
beyond reaching the SUA target for those in whom previously detected tophi have resolved. ${ }^{19}$

\section{Management of Gout Flares}

Gout flares, which are intensely painful episodes of self-limited arthritis, are usually the first clinical manifestation of gout. They are by far the most important manifestation of the disease for patients, and are the primary burden of this disease. Gout flares occur when MSU crystals activate the NLRP3 inflammasome, often in conjunction with a $2^{\text {nd }}$ signal such as certain free fatty acids, leading to elaboration of interleukin(IL)- $1 \beta$ release. ${ }^{81}$ The presence of MSU crystals alone is insufficient to cause gout flares as they can be detected in the synovial fluid of asymptomatic joints. Several factors have been identified that increase the risk of gout flares, including dietary factors (e.g., animal-derived purines, alcohol), hospitalizations (especially in the setting of surgery), and diuretics, among others. It is also well-recognized that initiation of ULT leads to an increase of gout flares in the short term. It is generally thought that fluctuations in SUA levels contribute to gout flares. Patients should be counseled regarding avoidance of pertinent dietary and lifestyle triggers. ${ }^{19,82}$ Such a preventive strategy may be particularly important for patients with CKD who often have fewer therapeutic options for adequately treating gout flares.

Treatment options for gout flares in the US include colchicine, NSAIDs, glucocorticoids (oral, intra-articular, intramuscular, intravenous), and subcutaneous or intramuscular adrenocorticotropic hormone (ACTH), though there is limited evidence for this latter option. IL-1 antagonism with canakinumab is an approach approved by the EMA for management of gout flares, but not yet approved in the US. ${ }^{83-85}$ Anakinra is occasionally used off-label in the US in patients for whom the other therapies cannot be used. Regardless of which therapeutic approach is used, the earlier the treatment is started, the faster the flare is brought under control. Local ice therapy can be used adjunctively. ${ }^{86} \mathrm{~A}$ "medications-in-thepocket" strategy should be encouraged for patients who understand their disease well to start treatment at the first signs of a flare; often immediate initiation of gout flare therapy can abort the attack entirely. General principles to consider for gout flare management are highlighted in Box 2 and specific considerations for patients with CKD are reviewed in Table 3 for each drug.

\section{Box 2}

\section{General principles for gout flare management}

\section{Treatment options}

- $\quad$ Colchicine

- $\quad$ Non-steroidal anti-inflammatory drugs

- $\quad$ Glucocorticoids (PO, IA, IM, IV)

- $\quad \mathrm{ACTH}(\mathrm{SC}, \mathrm{IM})$

- Interleukin-1 inhibitors (off-label in the US)

- $\quad$ Ice 
Time to start

- Immediately - "medications-in-the-pocket". Note, colchicine is less effective if started $>24$ hours after a flare has started

Dose

- $\quad$ High dose, then taper

\section{Duration}

- 7-14 days (until flare resolves; otherwise a rebound flare can occur)

\section{Urate-lowering therapy}

- $\quad$ No interruption

PO: per os, oral; IA: intra-articular; IM: intramuscular; IV: intravenous; ACTH: adrenocorticotropic hormone; SC: subcutaneous.

Colchicine-Colchicine is most effective for managing gout flares when started within the first 36 hours based on its mechanism of action, pharmacokinetics and clinical data. ${ }^{87}$ The recommended regimen for individuals with normal kidney function is $1.2 \mathrm{mg}$ at the first sign of a gout flare followed by $0.6 \mathrm{mg}$ one hour later based on fairly recent clinical trial data demonstrating similar efficacy and lower side effects with this strategy compared with a higher dose strategy. ${ }^{19,88}$ Although colchicine was used off-label for decades to manage gout flares, this more recent trial led to FDA-approval of Colcrys for this new indication, with a resultant marked increase in price and difficulty in obtaining generic colchicine. ${ }^{89}$ After this initial therapy, colchicine should be continued once or twice daily until resolution of the flare, or other gout flare therapy should be used.

For patients with CKD, colchicine must be used at lower doses with a number of caveats. Specifically, with $\mathrm{CrCl} \geq 30 \mathrm{~mL} / \mathrm{min}$, dose adjustment is not required. Per the FDA approved package insert, for $\mathrm{CrCl}<30 \mathrm{~mL} / \mathrm{min}$, dose reduction is not required, but a treatment course should not be repeated within a two-week period. For patients treated with hemodialysis, the FDA insert states that only a single $0.6 \mathrm{mg}$ dose should be used, and also not repeated within a two-week period; the same approach should be used for peritoneal dialysis patients. Importantly, if colchicine is already used for prophylaxis, it should not be used to treat a gout flare in CKD patients. The risk of neuromyotoxicity increases with declining kidney function and with concomitant use of many medications, including cyclosporine and lipidlowering medications such as statins and fibrates (Box 3).

\section{Box 3}

\section{Colchicine toxicity manifestations and risk factors}

\section{Toxicity Manifestations}

- $\quad$ Neuromuscular toxicity

May manifest as mildly as a tingling sensation or a subjective weakness or severely as overt peripheral neuropathy with axonal degeneration and 


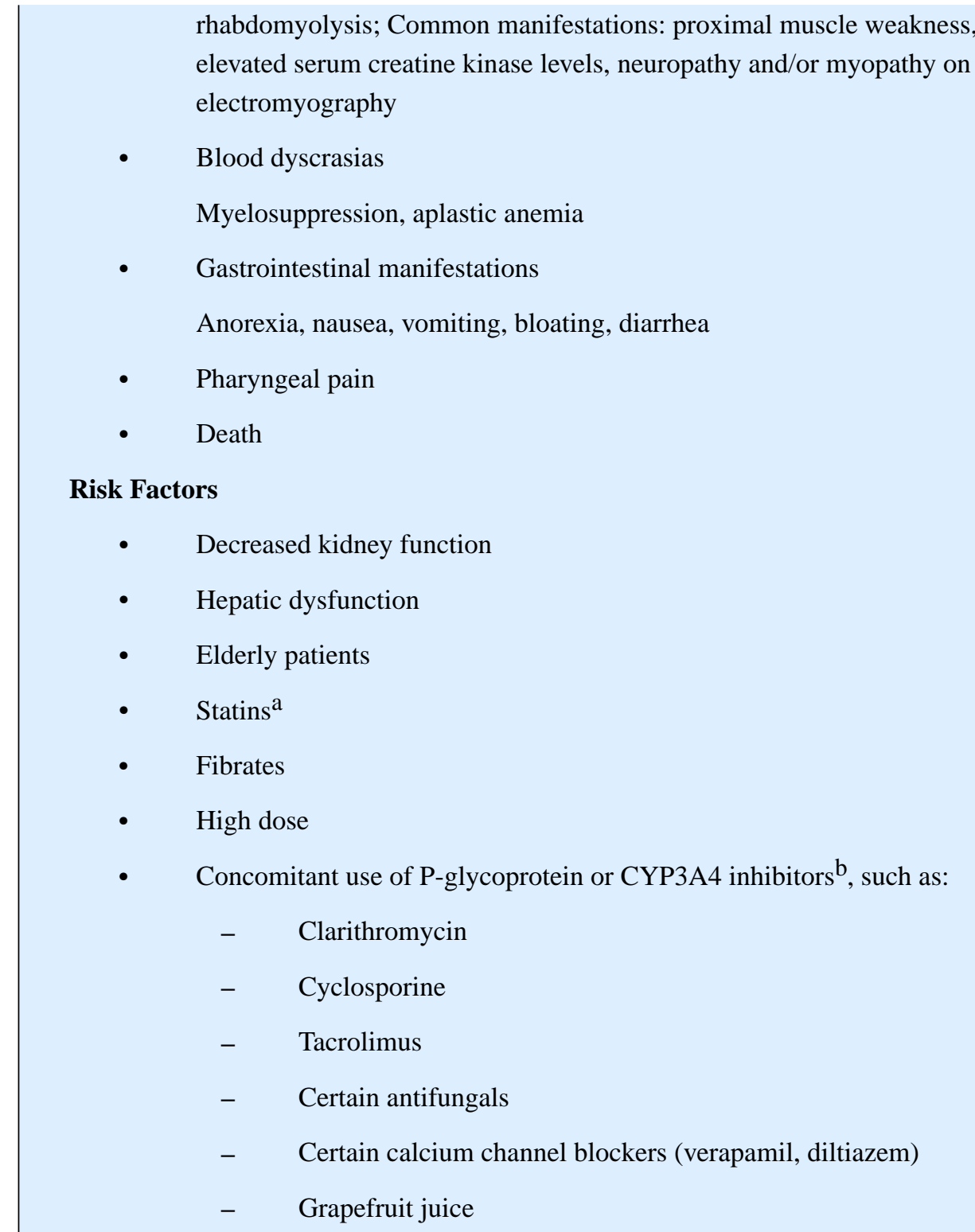

Special alert

Concomitant use of colchicine with P-glycoprotein or CYP3A4 inhibitors, especially clarithromycin, is contraindicated in patients with chronic kidney disease as it can result in death 90

Non-steroidal anti-inflammatory drugs-There are no data to suggest that one NSAID is more efficacious than another. NSAIDs generally are avoided in individuals with CKD, particularly those with advanced CKD not receiving dialysis. Clinicians may consider

\footnotetext{
ancreased risk of myopathy is thought to be due to pharmacodynamics factors and/or competition for CYP450 or P-glycoprotein, and possible effects of impaired statin elimination via CYP450 and/or drug transporter (e.g., P-glycoprotein inhibition). ${ }^{91}$ There is increased risk of myopathy/rhabdomyolysis with atorvastatin, fluvastatin, lovastatin, pravastatin and simvastatin. ${ }^{92}$

${ }^{\mathrm{b}}$ Colchicine metabolism is performed by these systems, with colchicine being considered a major substrate of CYP3A4.
} 
avoidance of NSAIDs in patients with concomitant diabetes mellitus even in the absence of obvious CKD given the high risk of kidney disease in such patients. Frequent use of NSAIDs for gout flare management can contribute to kidney disease. Cardiovascular risk and gastrointestinal bleeding risk need to be considered when NSAIDs are used, as for a non-dialysis population.

Glucocorticoids-When considering kidney safety, glucocorticoids may be the safest option for patients with CKD, remaining highly effective regardless of flare duration. A common regimen is to start with $0.5 \mathrm{mg} / \mathrm{kg}$ of body weight per day for the first few days, followed by progressive tapering. ${ }^{9,19}$ Intra-articular glucocorticoid injection is preferable when only one or two joints are affected. Due to cross-reactivity with the mineralocorticoid receptor, there may be an increased risk of heart failure with many glucocorticoids, likely due to increased renal sodium avidity. Accordingly, for patients with concomitant CHF, dexamethasone may be the preferred formulation if the intra-articular route is not possible because it is considered to have the least mineralocorticoid potency.

Adrenocorticotropic hormone-Parenteral ACTH (subcutaneous or intramuscular) is considered an appropriate alternative to treat gout flares in patients who have restrictions to oral drugs, with no recommendation of dose adjustment in CKD, though its use lacks the support of rigorous clinical trial data. ${ }^{19}$

It is not uncommon for a patient with severe CKD to have limited improvement of their gout flare with the recommended lower doses of colchicine. Since NSAIDs are contraindicated, that leaves glucocorticoids as the primary option, though off-label use of the IL-1 antagonist, anakinra, is employed in some patients, particularly when glucocorticoids also cannot be used.

Additional special considerations for the management of gout in kidney transplant patients are shown in Box 4.

\section{Box 4}

Additional special considerations for the management of gout in kidney transplant patients.

\section{Immunosuppressant Drugs}

- The use of xanthine oxidase inhibitors (allopurinol and febuxostat) is contraindicated with concomitant purine analogues, such as azathioprine and mercaptopurine, since this combination can result in higher and potentially toxic plasma concentrations of these drugs, leading to bone marrow suppression.

- $\quad$ Preferably avoid the hyperuricemic effects of cyclosporine.

- $\quad$ As such, mycophenolate mofetil should generally be the preferred immunosuppressant for gout patients with a kidney transplant.

\footnotetext{
*There are limited data regarding gout management in kidney transplant patients.
} 


\section{Urate-Lowering Therapy}

- All available urate-lowering drugs may be considered, according to current level of kidney function.

\section{Anti-Inflammatory Prophylaxis and/or Treatment of a Gout Flare}

- $\quad$ NSAIDs should be used with caution and close monitoring of kidney function, considering their effects on kidney hemodynamics.

- Colchicine should be avoided in combination with cyclosporine and tacrolimus due to an increased risk of colchicine myotoxicity.

\section{THE RELATION OF URIC ACID AND ULT TO KIDNEY OUTCOMES}

CKD leads to hyperuricemia due to decreased urinary excretion of UA. Hyperuricemia also may induce kidney dysfunction and contribute to CKD progression through a number of potential mechanisms. It is possible that controlling hyperuricemia, especially if achieved early, may reduce kidney disease risk.

\section{Mechanisms of hyperuricemia-induced kidney damage}

Hyperuricemia may cause endothelial dysfunction, reflecting the effects of a reduction of nitric oxide bioavailability, the stimulation of oxidative stress, and the activation of the renin-angiotensin system. ${ }^{3,93-95}$ Oxidative stress can stimulate smooth muscle cell proliferation of the afferent arterioles, thereby decreasing kidney perfusion. How much of these vascular effects are due to UA itself versus xanthine oxidase remains controversial. ${ }^{93}$ Nonetheless, hyperuricemia induced in a rat model results in systemic hypertension, primary kidney arteriolopathy, and glomerular hypertension and hypertrophy, with resultant kidney hypoperfusion and eventual tubulointerstitial inflammation and fibrosis (Box 5).${ }^{96-100}$ When hyperuricemia was prevented or corrected to normouricemia early in the course of disease with allopurinol, febuxostat or benziodarone (an uricosuric), these manifestations were prevented. ${ }^{96-101}$ In another rat model, allopurinol and benzbromarone limited the kidney damage caused by cyclosporine. ${ }^{102}$ The effects of uricosurics (benziodarone, benzbromarone) in these experiments support the direct effects of UA rather than these effects being simply due to xanthine oxidase.

\section{Box 5}

\section{Mechanisms by which hyperuricemia may contribute to kidney damage}

Reduced nitric oxide bioavailability

Stimulation of oxidative stress

Activation of the renin-angiotensin system

Systemic and glomerular hypertension

Kidney vasculopathy 
Tubulointerstitial inflammation and fibrosis

\section{Hyperuricemia and kidney endpoints in observational studies}

Though many observational studies have identified associations between hyperuricemia and CKD onset or progression, multiple others have not. ${ }^{103-126}$ In a Japanese study of 48,177 subjects, SUA $\ 6 \mathrm{mg} / \mathrm{dL}$ was an independent predictor of end-stage kidney disease in women, ${ }^{104}$ and an increase in SUA over 10 years was an independent risk factor for eGFR decline. ${ }^{115}$ Similarly, higher baseline SUA was also associated with kidney function decline in 16,186 patients with hyperuricemia enrolled in the Kaiser Permanente Southern California Health Plan. ${ }^{116}$ Complementing these findings, hyperuricemia in healthy subjects free of kidney dysfunction at baseline in 3 large cohorts was associated with higher risk of developing kidney disease. ${ }^{107,108}$ On the other hand, several observational studies have failed to identify a significant relation of SUA to CKD. ${ }^{121-126}$ For example, in the Modification of Diet in Renal Disease Study, which followed 840 subjects with eGFR between 13 and $55 \mathrm{~mL} / \mathrm{min}$ for up to 3.5 years, baseline SUA was not associated with CKD progression. ${ }^{121}$ The Cardiovascular Health Study, a prospective community-based cohort of 4610 subjects followed for a mean of 6.6 years, found no association between hyperuricemia and incident $\mathrm{CKD}$, although there was a modest association with CKD progression. ${ }^{106}$

\section{Cohort Studies of ULT and Kidney Disease}

Several observational studies have evaluated the effect of ULT on kidney function among subjects with normal kidney function and among patients with varying degrees of CKD and varying etiologies of kidney dysfunction (Table 4). While some are promising, definitive conclusions cannot be drawn from these observational studies of hyperuricemia and/or ULT on kidney effects, reflecting potential residual confounding and other biases including publication bias. Well-conducted clinical trials are needed for more valid insights to be drawn.

\section{Randomized trial data of kidney effects of ULT}

Only a few randomized clinical trials (Table 5) have assessed the effect of ULT, primarily allopurinol, on kidney outcomes. The febuxostat development program offered opportunity to gain insights into the effects of ULT on kidney function in the context of blinded randomized trials. However, while many trials were large, the numbers with CKD were small, subjects with advanced kidney disease (eGFR $<30 \mathrm{~mL} / \mathrm{min} / 1.73 \mathrm{~m}^{2}$ ) were excluded, and kidney endpoints were not specifically reported as part of the main RCT publications, but rather as part of open-label extension studies which have the inherent validity issues of observational cohort studies.

In summary, the interpretation of the evidence to date regarding the role of UA in kidney disease and the potential renoprotective effect of urate-lowering is hampered by lack of high level evidence. Studies to date have largely evaluated allopurinol and febuxostat, which are both XOIs; thus, whether beneficial effects on kidney disease noted in some observational studies are truly related to lowering of urate versus inhibition of xanthine oxidase cannot be discerned. Evaluation of the effects of a uricosuric agent in the context of kidney endpoints 
would provide further insights as to whether UA-lowering itself versus xanthine oxidase inhibition is the mechanism by which there appears to be promising renoprotective effects. Nonetheless, at the present time, treatment guidelines do not recommend treating asymptomatic hyperuricemia. Sufficiently powered, well-conducted, double-blinded, placebo-controlled randomized trials are needed to provide definitive direction into this important matter.

\section{CASE REVIEW}

For this patient, the first goal is to treat the current gout flare. Given his kidney disease and CHF, the optimal treatment would be intra-articular injection of the left knee and right $1^{\text {st }}$ MTP joint. In lieu of that, a course of dexamethasone can be considered for its lower mineralocorticoid potency to minimize the risk of CHF exacerbation. Colchicine should be avoided since he already uses it for prophylaxis. Colchicine $0.6 \mathrm{mg}$ every other day was continued for prophylaxis, and the allopurinol dose was kept stable until 2 weeks after the end of this gout flare, at which point his dose of allopurinol was increased to $200 \mathrm{mg}$ daily, and further up-titrated based on regular monitoring of his SUA levels. He was also counseled regarding adjunctive lifestyle factors. At a dose of $450 \mathrm{mg} / \mathrm{d}$, his SUA level was $5.6 \mathrm{mg} / \mathrm{dL}$. Having achieved the target of $<6 \mathrm{mg} / \mathrm{dL}$ (since he has no tophi), he was maintained on this dose. After six months of his SUA remaining $<6 \mathrm{mg} / \mathrm{dL}$, colchicine was discontinued. After a year of therapy, he did not experience any further gout flares.

\section{Acknowledgments}

Support: Dr. Vargas-Santos received a fellowship funding from Conselho Nacional de Desenvolvimento Científico e Tecnológico (CNPq), Ministry of Science, Technology and Innovation of Brazil. Dr. Neogi's work was supported by the NIH grant AR 47785. The funders had no role in study design; collection, analysis, and interpretation of data; writing the report; and the decision to submit the report for publication.

Financial disclosure: The authors declare that they have no relevant financial interests.

Peer Review: Evaluated by 2 peer reviewers, Deputy Editor Weiner, and Editor-in-Chief Levey.

\section{References}

1. Kuo CF, Grainge MJ, Zhang W, Doherty M. Global epidemiology of gout: prevalence, incidence and risk factors. Nat Rev Rheumatol. 2015; 11:649-62. [PubMed: 26150127]

2. Zhu Y, Pandya BJ, Choi HK. Prevalence of gout and hyperuricemia in the US general population: the National Health and Nutrition Examination Survey 2007-2008. Arthritis Rheum. 2011; 63:3136-41. [PubMed: 21800283]

3. Johnson RJ. Why focus on uric acid? Curr Med Res Opin. 2015; 31(Suppl 2):3-7. [PubMed: 26414730]

4. Roughley MJ, Belcher J, Mallen CD, Roddy E. Gout and risk of chronic kidney disease and nephrolithiasis: meta-analysis of observational studies. Arthritis Res Ther. 2015; 17:90. [PubMed: 25889144]

5. Krishnan E. Reduced glomerular function and prevalence of gout: NHANES 2009-10. PLoS One. 2012; 7:e50046. [PubMed: 23209642]

6. Zhu Y, Pandya BJ, Choi HK. Comorbidities of gout and hyperuricemia in the US general population: NHANES 2007-2008. Am J Med. 2012; 125:679-87. e1. [PubMed: 22626509]

7. Fraser SD, Roderick PJ, May CR, et al. The burden of comorbidity in people with chronic kidney disease stage 3: a cohort study. BMC Nephrol. 2015; 16:193. [PubMed: 26620131] 
8. Dalbeth N, Merriman TR, Stamp LK. Gout. Lancet. 2016

9. Neogi T. Clinical practice. Gout N Engl J Med. 2011; 364:443-52. [PubMed: 21288096]

10. Hak AE, Curhan GC, Grodstein F, Choi HK. Menopause, postmenopausal hormone use and risk of incident gout. Ann Rheum Dis. 2010; 69:1305-9. [PubMed: 19592386]

11. Vargas-Santos AB, Zhang Y, Lu N, et al. Patterns of Joint Involvement in Gout Flares. Arthritis Rheumatol. 2016; 68(suppl 10) [Accessed November 23, 2016] http://acrabstracts.org/abstract/ patterns-of-joint-involvement-in-gout-flares/.

12. De Souza A, Fernandes V, Ferrari AJ. Female gout: clinical and laboratory features. J Rheumatol. 2005; 32:2186-8. [PubMed: 16265700]

13. Forbess LJ, Fields TR. The broad spectrum of urate crystal deposition: unusual presentations of gouty tophi. Semin Arthritis Rheum. 2012; 42:146-54. [PubMed: 22522111]

14. De Leonardis F, Govoni M, Colina M, Bruschi M, Trotta F. Elderly-onset gout: a review. Rheumatol Int. 2007; 28:1-6. [PubMed: 17653719]

15. Abhishek A. Calcium pyrophosphate deposition disease: a review of epidemiologic findings. Curr Opin Rheumatol. 2016; 28:133-9. [PubMed: 26626724]

16. Neogi T, Jansen TL, Dalbeth N, et al. 2015 Gout classification criteria: an American College of Rheumatology/European League Against Rheumatism collaborative initiative. Ann Rheum Dis. 2015; 74:1789-98. [PubMed: 26359487]

17. Neogi T, Jansen TL, Dalbeth N, et al. 2015 Gout Classification Criteria: an American College of Rheumatology/European League Against Rheumatism collaborative initiative. Arthritis Rheumatol. 2015; 67:2557-68. [PubMed: 26352873]

18. Khanna D, Fitzgerald JD, Khanna PP, et al. 2012 American College of Rheumatology guidelines for management of gout. Part 1: systematic nonpharmacologic and pharmacologic therapeutic approaches to hyperuricemia. Arthritis Care Res (Hoboken). 2012; 64:1431-46. [PubMed: 23024028]

19. Khanna D, Khanna PP, Fitzgerald JD, et al. 2012 American College of Rheumatology guidelines for management of gout. Part 2: therapy and antiinflammatory prophylaxis of acute gouty arthritis. Arthritis Care Res (Hoboken). 2012; 64:1447-61. [PubMed: 23024029]

20. Zhang W, Doherty M, Bardin T, et al. EULAR evidence based recommendations for gout. Part II: Management. Report of a task force of the EULAR Standing Committee for International Clinical Studies Including Therapeutics (ESCISIT). Ann Rheum Dis. 2006; 65:1312-24. [PubMed: 16707532]

21. Jordan KM, Cameron JS, Snaith M, et al. British Society for Rheumatology and British Health Professionals in Rheumatology guideline for the management of gout. Rheumatology (Oxford). 2007; 46:1372-4. [PubMed: 17522099]

22. Sivera F, Andres M, Carmona L, et al. Multinational evidence-based recommendations for the diagnosis and management of gout: integrating systematic literature review and expert opinion of a broad panel of rheumatologists in the 3e initiative. Ann Rheum Dis. 2014; 73:328-35. [PubMed: 23868909]

23. Emmerson BT. The management of gout. N Engl J Med. 1996; 334:445-51. [PubMed: 8552148]

24. Lindsay K, Gow P, Vanderpyl J, Logo P, Dalbeth N. The experience and impact of living with gout: a study of men with chronic gout using a qualitative grounded theory approach. J Clin Rheumatol. 2011; 17:1-6. [PubMed: 21169857]

25. Doherty M, Jansen TL, Nuki G, et al. Gout: why is this curable disease so seldom cured? Ann Rheum Dis. 2012; 71:1765-70. [PubMed: 22863577]

26. Ohno I, Ichida K, Okabe H, et al. Frequency of gouty arthritis in patients with end-stage renal disease in Japan. Intern Med. 2005; 44:706-9. [PubMed: 16093591]

27. Ifudu O, Tan CC, Dulin AL, Delano BG, Friedman EA. Gouty arthritis in end-stage renal disease: clinical course and rarity of new cases. Am J Kidney Dis. 1994; 23:347-51. [PubMed: 8128934]

28. Dalbeth N, Stamp L. Allopurinol dosing in renal impairment: walking the tightrope between adequate urate lowering and adverse events. Semin Dial. 2007; 20:391-5. [PubMed: 17897242]

29. Wright DF, Doogue MP, Barclay ML, et al. A population pharmacokinetic model to predict oxypurinol exposure in patients on haemodialysis. Eur J Clin Pharmacol. 2017; 73:71-8. [PubMed: 27683090] 
30. Horikoshi R, Akimoto T, Inoue M, Morishita Y, Kusano E. Febuxostat for hyperuricemia: experience with patients on chronic hemodialysis treatment. Clin Exp Nephrol. 2013; 17:149-50. [PubMed: 23292179]

31. Akimoto T, Morishita Y, Ito C, et al. Febuxostat for hyperuricemia in patients with advanced chronic kidney disease. Drug Target Insights. 2014; 8:39-43. [PubMed: 25210423]

32. Mitsuboshi S, Yamada H, Nagai K, Okajima H. Switching from allopurinol to febuxostat: efficacy and tolerability in hemodialysis patients. J Pharm Health Care Sci. 2015; 1:28. [PubMed: 26819739]

33. Frassetto LA, Gibson S. Febuxostat and Increased Dialysis as a Treatment for Severe Tophaceous Gout in a Hemodialysis Patient. Case Rep Nephrol. 2016; 2016:9106935. [PubMed: 27200198]

34. Lim DH, Oh JS, Ahn SM, et al. Febuxostat in Hyperuricemic Patients With Advanced CKD. Am J Kidney Dis. 2016; 68:819-21. [PubMed: 27503183]

35. Bleyer AJ, Wright D, Alcorn H. Pharmacokinetics and pharmacodynamics of pegloticase in patients with end-stage renal failure receiving hemodialysis. Clin Nephrol. 2015; 83:286-92. [PubMed: 25816806]

36. Garg JP, Chasan-Taber S, Blair A, et al. Effects of sevelamer and calcium-based phosphate binders on uric acid concentrations in patients undergoing hemodialysis: a randomized clinical trial. Arthritis Rheum. 2005; 52:290-5. [PubMed: 15641045]

37. Ohno I, Yamaguchi Y, Saikawa H, et al. Sevelamer decreases serum uric acid concentration through adsorption of uric acid in maintenance hemodialysis patients. Intern Med. 2009; 48:41520. [PubMed: 19293539]

38. Hill EM, Sky K, Sit M, Collamer A, Higgs J. Does starting allopurinol prolong acute treated gout? A randomized clinical trial. J Clin Rheumatol. 2015; 21:120-5. [PubMed: 25807090]

39. Taylor TH, Mecchella JN, Larson RJ, Kerin KD, Mackenzie TA. Initiation of allopurinol at first medical contact for acute attacks of gout: a randomized clinical trial. Am J Med. 2012; 125:112634. e7. [PubMed: 23098865]

40. Hande KR, Noone RM, Stone WJ. Severe allopurinol toxicity. Description and guidelines for prevention in patients with renal insufficiency. Am J Med. 1984; 76:47-56.

41. Rees F, Hui M, Doherty M. Optimizing current treatment of gout. Nat Rev Rheumatol. 2014; 10:271-83. [PubMed: 24614592]

42. Rees F, Jenkins W, Doherty M. Patients with gout adhere to curative treatment if informed appropriately: proof-of-concept observational study. Ann Rheum Dis. 2013; 72:826-30. [PubMed: 22679303]

43. Dalbeth N, Kumar S, Stamp L, Gow P. Dose adjustment of allopurinol according to creatinine clearance does not provide adequate control of hyperuricemia in patients with gout. J Rheumatol. 2006; 33:1646-50. [PubMed: 16783857]

44. Reinders MK, Haagsma C, Jansen TL, et al. A randomised controlled trial on the efficacy and tolerability with dose escalation of allopurinol 300-600 mg/day versus benzbromarone 100-200 $\mathrm{mg}$ /day in patients with gout. Ann Rheum Dis. 2009; 68:892-7. [PubMed: 18633127]

45. Stamp LK, O'Donnell JL, Zhang M, et al. Using allopurinol above the dose based on creatinine clearance is effective and safe in patients with chronic gout, including those with renal impairment. Arthritis Rheum. 2011; 63:412-21. [PubMed: 21279998]

46. Stamp LK, Day RO, Yun J. Allopurinol hypersensitivity: investigating the cause and minimizing the risk. Nat Rev Rheumatol. 2016; 12:235-42. [PubMed: 26416594]

47. Paisansinsup T, Breitenstein MK, Schousboe JT. Association between adverse reactions to allopurinol and exposures to high maintenance doses: implications for management of patients using allopurinol. J Clin Rheumatol. 2013; 19:180-6. [PubMed: 23669799]

48. Stamp LK, Taylor WJ, Jones PB, et al. Starting dose is a risk factor for allopurinol hypersensitivity syndrome: a proposed safe starting dose of allopurinol. Arthritis Rheum. 2012; 64:2529-36. [PubMed: 22488501]

49. Yun J, Mattsson J, Schnyder K, et al. Allopurinol hypersensitivity is primarily mediated by dosedependent oxypurinol-specific T cell response. Clin Exp Allergy. 2013; 43:1246-55. [PubMed: 24152157] 
50. Somkrua R, Eickman EE, Saokaew S, Lohitnavy M, Chaiyakunapruk N. Association of HLAB*5801 allele and allopurinol-induced Stevens Johnson syndrome and toxic epidermal necrolysis: a systematic review and meta-analysis. BMC Med Genet. 2011; 12:118. [PubMed: 21906289]

51. Kim SC, Newcomb C, Margolis D, Roy J, Hennessy S. Severe cutaneous reactions requiring hospitalization in allopurinol initiators: a population-based cohort study. Arthritis Care Res (Hoboken). 2013; 65:578-84. [PubMed: 22899369]

52. Rundles RW. Allopurinol in gouty nephropathy and renal dialysis. Ann Rheum Dis. 1966; 25:6946. [PubMed: 5958701]

53. Hayes CP Jr, Metz EN, Robinson RR, Rundles RW. The Use of Allopurinol (Hpp) to Control Hyperuricemia in Patients on Chronic Intermittent Hemodialysis. Trans Am Soc Artif Intern Organs. 1965; 11:247-54. [PubMed: 14329092]

54. Day RO, Kannangara DR, Hayes JM, Furlong TJ. Successful use of allopurinol in a patient on dialysis. BMJ Case Rep. 2012; 2012

55. Jalalzadeh M, Nurcheshmeh Z, Mohammadi R, Mousavinasab N, Ghadiani MH. The effect of allopurinol on lowering blood pressure in hemodialysis patients with hyperuricemia. J Res Med Sci. 2012; 17:1039-46. [PubMed: 23833578]

56. Becker MA, Schumacher HR Jr, Wortmann RL, et al. Febuxostat compared with allopurinol in patients with hyperuricemia and gout. N Engl J Med. 2005; 353:2450-61. [PubMed: 16339094]

57. Schumacher HR Jr, Becker MA, Wortmann RL, et al. Effects of febuxostat versus allopurinol and placebo in reducing serum urate in subjects with hyperuricemia and gout: a 28-week, phase III, randomized, double-blind, parallel-group trial. Arthritis Rheum. 2008; 59:1540-8. [PubMed: 18975369]

58. Becker MA, Schumacher HR, MacDonald PA, Lloyd E, Lademacher C. Clinical efficacy and safety of successful longterm urate lowering with febuxostat or allopurinol in subjects with gout. J Rheumatol. 2009; 36:1273-82. [PubMed: 19286847]

59. Becker MA, Schumacher HR, Espinoza LR, et al. The urate-lowering efficacy and safety of febuxostat in the treatment of the hyperuricemia of gout: the CONFIRMS trial. Arthritis Res Ther. 2010; 12:R63. [PubMed: 20370912]

60. Saag KG, Whelton A, Becker MA, MacDonald P, Hunt B, Gunawardhana L. Impact of Febuxostat on Renal Function in Gout Patients With Moderate-to-Severe Renal Impairment. Arthritis Rheumatol. 2016; 68:2035-43. [PubMed: 26894653]

61. Sofue T, Inui M, Hara T, et al. Efficacy and safety of febuxostat in the treatment of hyperuricemia in stable kidney transplant recipients. Drug Des Devel Ther. 2014; 8:245-53.

62. Tojimbara T, Nakajima I, Yashima J, Fuchinoue S, Teraoka S. Efficacy and safety of febuxostat, a novel nonpurine selective inhibitor of xanthine oxidase for the treatment of hyperuricemia in kidney transplant recipients. Transplant Proc. 2014; 46:511-3. [PubMed: 24656001]

63. Chou HY, Chen CB, Cheng CY, et al. Febuxostat-associated drug reaction with eosinophilia and systemic symptoms (DRESS). J Clin Pharm Ther. 2015; 40:689-92. [PubMed: 26365588]

64. Febuxostat (Adenuric). Toxic epidermal necrolysis and severe hypersensitivity reactions added to the EU SPC. Prescrire Int. 2015; 24:153. [PubMed: 26436167]

65. Health Canada. [Accessed August 4, 2016] Summary Safety Review - ULORIC (febuxostat) Assessing a Possible Risk of Drug Reaction/Rash with Eosinophilia and Systemic Symptoms (DRESS). http://www.hc-sc.gc.ca/dhp-mps/medeff/reviews-examens/uloric3-eng.php

66. European Medicines Agency. Adenuric: EPAR - Product Information (last updated: 05 February 2016). Retrieved August 04, 2016 from http://www.ema.europa.eu/docs/en_GB/document_library/ EPAR_-_Product_Information/human/000777/WC500021812.pdf

67. Paschou E, Gavriilaki E, Papaioannou G, Tsompanakou A, Kalaitzoglou A, Sabanis N. Febuxostat hypersensitivity: another cause of DRESS syndrome in chronic kidney disease? Eur Ann Allergy Clin Immunol. 2016; 48:251-5. [PubMed: 27852432]

68. Gandhi PK, Gentry WM, Bottorff MB. Cardiovascular thromboembolic events associated with febuxostat: investigation of cases from the FDA adverse event reporting system database. Semin Arthritis Rheum. 2013; 42:562-6. [PubMed: 23352248] 
69. Health Canada. [Accessed August 4, 2016] Summary Safety Review - ULORIC (febuxostat) Assessing the Potential Risk of Heart Failure. http://www.hc-sc.gc.ca/dhp-mps/medeff/reviewsexamens/uloric2-eng.php

70. White WB, Chohan S, Dabholkar A, Hunt B, Jackson R. Cardiovascular safety of febuxostat and allopurinol in patients with gout and cardiovascular comorbidities. Am Heart J. 2012; 164:14-20. [PubMed: 22795277]

71. MacDonald TM, Ford I, Nuki G, et al. Protocol of the Febuxostat versus Allopurinol Streamlined Trial (FAST): a large prospective, randomised, open, blinded endpoint study comparing the cardiovascular safety of allopurinol and febuxostat in the management of symptomatic hyperuricaemia. BMJ Open. 2014; 4:e005354.

72. Mitri G, Wittbrodt ET, Turpin RS, Tidwell BA, Schulman KL. Cost Comparison of UrateLowering Therapies in Patients with Gout and Moderate-to-Severe Chronic Kidney Disease. J Manag Care Spec Pharm. 2016; 22:326-36. [PubMed: 27023686]

73. Smolen LJ, Gahn JC, Mitri G, Shiozawa A. Febuxostat in the management of gout: a costeffectiveness analysis. J Med Econ. 2016; 19:265-76. [PubMed: 26535593]

74. Beard SM, von Scheele BG, Nuki G, Pearson IV. Cost-effectiveness of febuxostat in chronic gout. Eur J Health Econ. 2014; 15:453-63. [PubMed: 23719971]

75. Gandhi PK, Gentry WM, Ma Q, Bottorff MB. Cost-effectiveness analysis of allopurinol versus febuxostat in chronic gout patients: a U.S. payer perspective. J Manag Care Spec Pharm. 2015; 21:165-75. [PubMed: 25615006]

76. Faruque LI, Ehteshami-Afshar A, Wiebe N, Tjosvold L, Homik J, Tonelli M. A systematic review and meta-analysis on the safety and efficacy of febuxostat versus allopurinol in chronic gout. Semin Arthritis Rheum. 2013; 43:367-75. [PubMed: 24326033]

77. Kydd AS, Seth R, Buchbinder R, Edwards CJ, Bombardier C. Uricosuric medications for chronic gout. Cochrane Database Syst Rev. 2014:CD010457. [PubMed: 25392987]

78. Sundy JS, Baraf HS, Yood RA, et al. Efficacy and tolerability of pegloticase for the treatment of chronic gout in patients refractory to conventional treatment: two randomized controlled trials. JAMA. 2011; 306:711-20. [PubMed: 21846852]

79. Becker MA, Baraf HS, Yood RA, et al. Long-term safety of pegloticase in chronic gout refractory to conventional treatment. Ann Rheum Dis. 2013; 72:1469-74. [PubMed: 23144450]

80. Food and Drug Adminitration. [Accessed November 27, 2016] Colcrys Full Prescribing Information. http://www.accessdata.fda.gov/drugsatfda_docs/label/2015/022352s0221bl.pdf

81. Joosten LA, Netea MG, Mylona E, et al. Engagement of fatty acids with Toll-like receptor 2 drives interleukin-1beta production via the ASC/caspase 1 pathway in monosodium urate monohydrate crystal-induced gouty arthritis. Arthritis Rheum. 2010; 62:3237-48. [PubMed: 20662061]

82. Neogi T. Gout. Ann Intern Med. 2016; 165:ITC1-ITC16. [PubMed: 27380294]

83. Dumusc A, So A. Interleukin-1 as a therapeutic target in gout. Curr Opin Rheumatol. 2015; 27:156-63. [PubMed: 25633244]

84. Schlesinger N. Anti-interleukin-1 therapy in the management of gout. Curr Rheumatol Rep. 2014; 16:398. [PubMed: 24407823]

85. Tran TH, Pham JT, Shafeeq H, Manigault KR, Arya V. Role of interleukin-1 inhibitors in the management of gout. Pharmacotherapy. 2013; 33:744-53. [PubMed: 23553601]

86. Schlesinger N, Detry MA, Holland BK, et al. Local ice therapy during bouts of acute gouty arthritis. J Rheumatol. 2002; 29:331-4. [PubMed: 11838852]

87. Niel E, Scherrmann JM. Colchicine today. Joint Bone Spine. 2006; 73:672-8. [PubMed: 17067838]

88. Terkeltaub RA, Furst DE, Bennett K, Kook KA, Crockett RS, Davis MW. High versus low dosing of oral colchicine for early acute gout flare: Twenty-four-hour outcome of the first multicenter, randomized, double-blind, placebo-controlled, parallel-group, dose-comparison colchicine study. Arthritis Rheum. 2010; 62:1060-8. [PubMed: 20131255]

89. Kesselheim AS, Solomon DH. Incentives for drug development--the curious case of colchicine. N Engl J Med. 2010; 362:2045-7. [PubMed: 20393164] 
90. Hung IF, Wu AK, Cheng VC, et al. Fatal interaction between clarithromycin and colchicine in patients with renal insufficiency: a retrospective study. Clin Infect Dis. 2005; 41:291-300. [PubMed: 16007523]

91. Tufan A, Dede DS, Cavus S, Altintas ND, Iskit AB, Topeli A. Rhabdomyolysis in a patient treated with colchicine and atorvastatin. Ann Pharmacother. 2006; 40:1466-9. [PubMed: 16772404]

92. PL Detail-Document, Clinically Significant Statin Drug Interactions. Pharmacist's Letter/ Prescriber's Letter. Apr. 2012

93. Neogi T, George J, Rekhraj S, Struthers AD, Choi H, Terkeltaub RA. Are either or both hyperuricemia and xanthine oxidase directly toxic to the vasculature? A critical appraisal. Arthritis Rheum. 2012; 64:327-38. [PubMed: 21953377]

94. Khosla UM, Zharikov S, Finch JL, et al. Hyperuricemia induces endothelial dysfunction. Kidney Int. 2005; 67:1739-42. [PubMed: 15840020]

95. Yu MA, Sanchez-Lozada LG, Johnson RJ, Kang DH. Oxidative stress with an activation of the renin-angiotensin system in human vascular endothelial cells as a novel mechanism of uric acidinduced endothelial dysfunction. J Hypertens. 2010; 28:1234-42. [PubMed: 20486275]

96. Mazzali M, Hughes J, Kim YG, et al. Elevated uric acid increases blood pressure in the rat by a novel crystal-independent mechanism. Hypertension. 2001; 38:1101-6. [PubMed: 11711505]

97. Mazzali M, Kanellis J, Han L, et al. Hyperuricemia induces a primary renal arteriolopathy in rats by a blood pressure-independent mechanism. Am J Physiol Renal Physiol. 2002; 282:F991-7. [PubMed: 11997315]

98. Sanchez-Lozada LG, Tapia E, Avila-Casado C, et al. Mild hyperuricemia induces glomerular hypertension in normal rats. Am J Physiol Renal Physiol. 2002; 283:F1105-10. [PubMed: 12372787]

99. Nakagawa T, Mazzali M, Kang DH, et al. Hyperuricemia causes glomerular hypertrophy in the rat. Am J Nephrol. 2003; 23:2-7. [PubMed: 12373074]

100. Sanchez-Lozada LG, Tapia E, Santamaria J, et al. Mild hyperuricemia induces vasoconstriction and maintains glomerular hypertension in normal and remnant kidney rats. Kidney Int. 2005; 67:237-47. [PubMed: 15610247]

101. Sanchez-Lozada LG, Tapia E, Soto V, et al. Treatment with the xanthine oxidase inhibitor febuxostat lowers uric acid and alleviates systemic and glomerular hypertension in experimental hyperuricaemia. Nephrol Dial Transplant. 2008; 23:1179-85. [PubMed: 18048425]

102. Mazali FC, Johnson RJ, Mazzali M. Use of uric acid-lowering agents limits experimental cyclosporine nephropathy. Nephron Exp Nephrol. 2012; 120:e12-9. [PubMed: 22126908]

103. Iseki K, Oshiro S, Tozawa M, Iseki C, Ikemiya Y, Takishita S. Significance of hyperuricemia on the early detection of renal failure in a cohort of screened subjects. Hypertens Res. 2001; 24:6917. [PubMed: 11768729]

104. Iseki K, Ikemiya Y, Inoue T, Iseki C, Kinjo K, Takishita S. Significance of hyperuricemia as a risk factor for developing ESRD in a screened cohort. Am J Kidney Dis. 2004; 44:642-50. [PubMed: 15384015]

105. Domrongkitchaiporn S, Sritara P, Kitiyakara C, et al. Risk factors for development of decreased kidney function in a southeast Asian population: a 12-year cohort study. J Am Soc Nephrol. 2005; 16:791-9. [PubMed: 15677313]

106. Chonchol M, Shlipak MG, Katz R, et al. Relationship of uric acid with progression of kidney disease. Am J Kidney Dis. 2007; 50:239-47. [PubMed: 17660025]

107. Obermayr RP, Temml C, Gutjahr G, Knechtelsdorfer M, Oberbauer R, Klauser-Braun R. Elevated uric acid increases the risk for kidney disease. J Am Soc Nephrol. 2008; 19:2407-13. [PubMed: 18799720]

108. Weiner DE, Tighiouart H, Elsayed EF, Griffith JL, Salem DN, Levey AS. Uric acid and incident kidney disease in the community. J Am Soc Nephrol. 2008; 19:1204-11. [PubMed: 18337481]

109. Hsu CY, Iribarren C, McCulloch CE, Darbinian J, Go AS. Risk factors for end-stage renal disease: 25-year follow-up. Arch Intern Med. 2009; 169:342-50. [PubMed: 19237717]

110. See LC, Kuo CF, Chuang FH, et al. Serum uric acid is independently associated with metabolic syndrome in subjects with and without a low estimated glomerular filtration rate. J Rheumatol. 2009; 36:1691-8. [PubMed: 19531754] 
111. Bellomo G, Venanzi S, Verdura C, Saronio P, Esposito A, Timio M. Association of uric acid with change in kidney function in healthy normotensive individuals. Am J Kidney Dis. 2010; 56:26472. [PubMed: 20385436]

112. Ben-Dov IZ, Kark JD. Serum uric acid is a GFR-independent long-term predictor of acute and chronic renal insufficiency: the Jerusalem Lipid Research Clinic cohort study. Nephrol Dial Transplant. 2011; 26:2558-66. [PubMed: 21220750]

113. Yamada T, Fukatsu M, Suzuki S, Wada T, Joh T. Elevated serum uric acid predicts chronic kidney disease. Am J Med Sci. 2011; 342:461-6. [PubMed: 21760479]

114. Dawson J, Jeemon P, Hetherington L, et al. Serum uric acid level, longitudinal blood pressure, renal function, and long-term mortality in treated hypertensive patients. Hypertension. 2013; 62:105-11. [PubMed: 23690348]

115. Iseki K, Iseki C, Kinjo K. Changes in serum uric acid have a reciprocal effect on eGFR change: a 10-year follow-up study of community-based screening in Okinawa, Japan. Hypertens Res. 2013; 36:650-4. [PubMed: 23486166]

116. Levy GD, Rashid N, Niu F, Cheetham TC. Effect of urate-lowering therapies on renal disease progression in patients with hyperuricemia. J Rheumatol. 2014; 41:955-62. [PubMed: 24692523]

117. Rodenbach KE, Schneider MF, Furth SL, et al. Hyperuricemia and Progression of CKD in Children and Adolescents: The Chronic Kidney Disease in Children (CKiD) Cohort Study. Am J Kidney Dis. 2015; 66:984-92. [PubMed: 26209544]

118. Uchida S, Chang WX, Ota T, et al. Targeting Uric Acid and the Inhibition of Progression to EndStage Renal Disease--A Propensity Score Analysis. PLoS One. 2015; 10:e0145506. [PubMed: 26700005]

119. Yan D, Tu Y, Jiang F, et al. Uric Acid is independently associated with diabetic kidney disease: a cross-sectional study in a Chinese population. PLoS One. 2015; 10:e0129797. [PubMed: 26029914]

120. Chang YH, Lei CC, Lin KC, Chang DM, Hsieh CH, Lee YJ. Serum uric acid level as an indicator for CKD regression and progression in patients with type 2 diabetes mellitus-a 4.6-year cohort study. Diabetes Metab Res Rev. 2016; 32:557-64. [PubMed: 26590369]

121. Hunsicker LG, Adler S, Caggiula A, et al. Predictors of the progression of renal disease in the Modification of Diet in Renal Disease Study. Kidney Int. 1997; 51:1908-19. [PubMed: 9186882]

122. Weiner DE, Tighiouart H, Elsayed EF, et al. The relationship between nontraditional risk factors and outcomes in individuals with stage 3 to 4 CKD. Am J Kidney Dis. 2008; 51:212-23. [PubMed: 18215699]

123. Sturm G, Kollerits B, Neyer U, Ritz E, Kronenberg F, Group MS. Uric acid as a risk factor for progression of non-diabetic chronic kidney disease? The Mild to Moderate Kidney Disease (MMKD) Study. Exp Gerontol. 2008; 43:347-52. [PubMed: 18294794]

124. Madero M, Sarnak MJ, Wang X, et al. Uric acid and long-term outcomes in CKD. Am J Kidney Dis. 2009; 53:796-803. [PubMed: 19303683]

125. Chang WX, Asakawa S, Toyoki D, et al. Predictors and the Subsequent Risk of End-Stage Renal Disease - Usefulness of 30\% Decline in Estimated GFR over 2 Years. PLoS One. 2015; 10:e0132927. [PubMed: 26177463]

126. Kuriyama S, Maruyama Y, Nishio S, et al. Serum uric acid and the incidence of CKD and hypertension. Clin Exp Nephrol. 2015; 19:1127-34. [PubMed: 25967597]

127. Whelton A, Macdonald PA, Zhao L, Hunt B, Gunawardhana L. Renal function in gout: long-term treatment effects of febuxostat. J Clin Rheumatol. 2011; 17:7-13. [PubMed: 21169856]

128. Pai BH, Swarnalatha G, Ram R, Dakshinamurty KV. Allopurinol for prevention of progression of kidney disease with hyperuricemia. Indian J Nephrol. 2013; 23:280-6. [PubMed: 23960345]

129. Whelton A, MacDonald PA, Chefo S, Gunawardhana L. Preservation of renal function during gout treatment with febuxostat: a quantitative study. Postgrad Med. 2013; 125:106-14. [PubMed: 23391676]

130. Shibagaki Y, Ohno I, Hosoya T, Kimura K. Safety, efficacy and renal effect of febuxostat in patients with moderate-to-severe kidney dysfunction. Hypertens Res. 2014; 37:919-25. [PubMed: 24942770] 
131. Kim Y, Shin S, Kim K, Choi S, Lee K. Effect of Urate Lowering Therapy on Renal Disease Progression in Hyperuricemic Patients with Chronic Kidney Disease. J Rheumatol. 2015; 42:2143-8. [PubMed: 26428209]

132. Singh JA, Yu S. Are allopurinol dose and duration of use nephroprotective in the elderly? A Medicare claims study of allopurinol use and incident renal failure. Ann Rheum Dis. 2017; 76:133-9. [PubMed: 27296322]

133. Ma L, Wei L, Chen H, et al. Influence of urate-lowering therapies on renal handling of uric acid. Clin Rheumatol. 2016; 35:133-41. [PubMed: 25373449]

134. Gibson T, Rodgers V, Potter C, Simmonds HA. Allopurinol treatment and its effect on renal function in gout: a controlled study. Ann Rheum Dis. 1982; 41:59-65. [PubMed: 7039523]

135. Dahlof B, Devereux RB, Kjeldsen SE, et al. Cardiovascular morbidity and mortality in the Losartan Intervention For Endpoint reduction in hypertension study (LIFE): a randomised trial against atenolol. Lancet. 2002; 359:995-1003. [PubMed: 11937178]

136. Siu YP, Leung KT, Tong MK, Kwan TH. Use of allopurinol in slowing the progression of renal disease through its ability to lower serum uric acid level. Am J Kidney Dis. 2006; 47:51-9. [PubMed: 16377385]

137. Momeni A, Shahidi S, Seirafian S, Taheri S, Kheiri S. Effect of allopurinol in decreasing proteinuria in type 2 diabetic patients. Iran J Kidney Dis. 2010; 4:128-32. [PubMed: 20404423]

138. Kanbay M, Huddam B, Azak A, et al. A randomized study of allopurinol on endothelial function and estimated glomular filtration rate in asymptomatic hyperuricemic subjects with normal renal function. Clin J Am Soc Nephrol. 2011; 6:1887-94. [PubMed: 21784838]

139. Kao MP, Ang DS, Gandy SJ, et al. Allopurinol benefits left ventricular mass and endothelial dysfunction in chronic kidney disease. J Am Soc Nephrol. 2011; 22:1382-9. [PubMed: 21719783]

140. Shi Y, Chen W, Jalal D, et al. Clinical outcome of hyperuricemia in IgA nephropathy: a retrospective cohort study and randomized controlled trial. Kidney Blood Press Res. 2012; 35:153-60. [PubMed: 22116196]

141. Goicoechea M, de Vinuesa SG, Verdalles U, et al. Effect of allopurinol in chronic kidney disease progression and cardiovascular risk. Clin J Am Soc Nephrol. 2010; 5:1388-93. [PubMed: 20538833]

142. Goicoechea M, Garcia de Vinuesa S, Verdalles U, et al. Allopurinol and progression of CKD and cardiovascular events: long-term follow-up of a randomized clinical trial. Am J Kidney Dis. 2015; 65:543-9. [PubMed: 25595565]

143. Kim HA, Seo YI, Song YW. Four-week effects of allopurinol and febuxostat treatments on blood pressure and serum creatinine level in gouty men. J Korean Med Sci. 2014; 29:1077-81. [PubMed: 25120316]

144. Liu P, Chen Y, Wang B, Zhang F, Wang D, Wang Y. Allopurinol treatment improves renal function in patients with type 2 diabetes and asymptomatic hyperuricemia: 3-year randomized parallel-controlled study. Clin Endocrinol (Oxf). 2015; 83:475-82. [PubMed: 25400252]

145. Sircar D, Chatterjee S, Waikhom R, et al. Efficacy of Febuxostat for Slowing the GFR Decline in Patients With CKD and Asymptomatic Hyperuricemia: A 6-Month, Double-Blind, Randomized, Placebo-Controlled Trial. Am J Kidney Dis. 2015; 66:945-50. [PubMed: 26233732]

146. Tanaka K, Nakayama M, Kanno M, et al. Renoprotective effects of febuxostat in hyperuricemic patients with chronic kidney disease: a parallel-group, randomized, controlled trial. Clin Exp Nephrol. 2015; 19:1044-53. [PubMed: 25676011]

147. Sezai A, Soma M, Nakata K, et al. Comparison of febuxostat and allopurinol for hyperuricemia in cardiac surgery patients with chronic kidney disease (NU-FLASH trial for CKD). J Cardiol. 2015; 66:298-303. [PubMed: 25649025]

148. Bose B, Badve SV, Hiremath SS, et al. Effects of uric acid-lowering therapy on renal outcomes: a systematic review and meta-analysis. Nephrol Dial Transplant. 2014; 29:406-13. [PubMed: 24042021]

149. Sarris E, Bagiatudi G, Stavrianaki D, et al. Use of allopurinol in slowing the progression of chronic renal disease (abstract). Nephrol Dial Transplant. 2007; 22:vi61. 
150. Kanji T, Gandhi M, Clase CM, Yang R. Urate lowering therapy to improve renal outcomes in patients with chronic kidney disease: systematic review and meta-analysis. BMC Nephrol. 2015; 16:58. [PubMed: 25928556] 


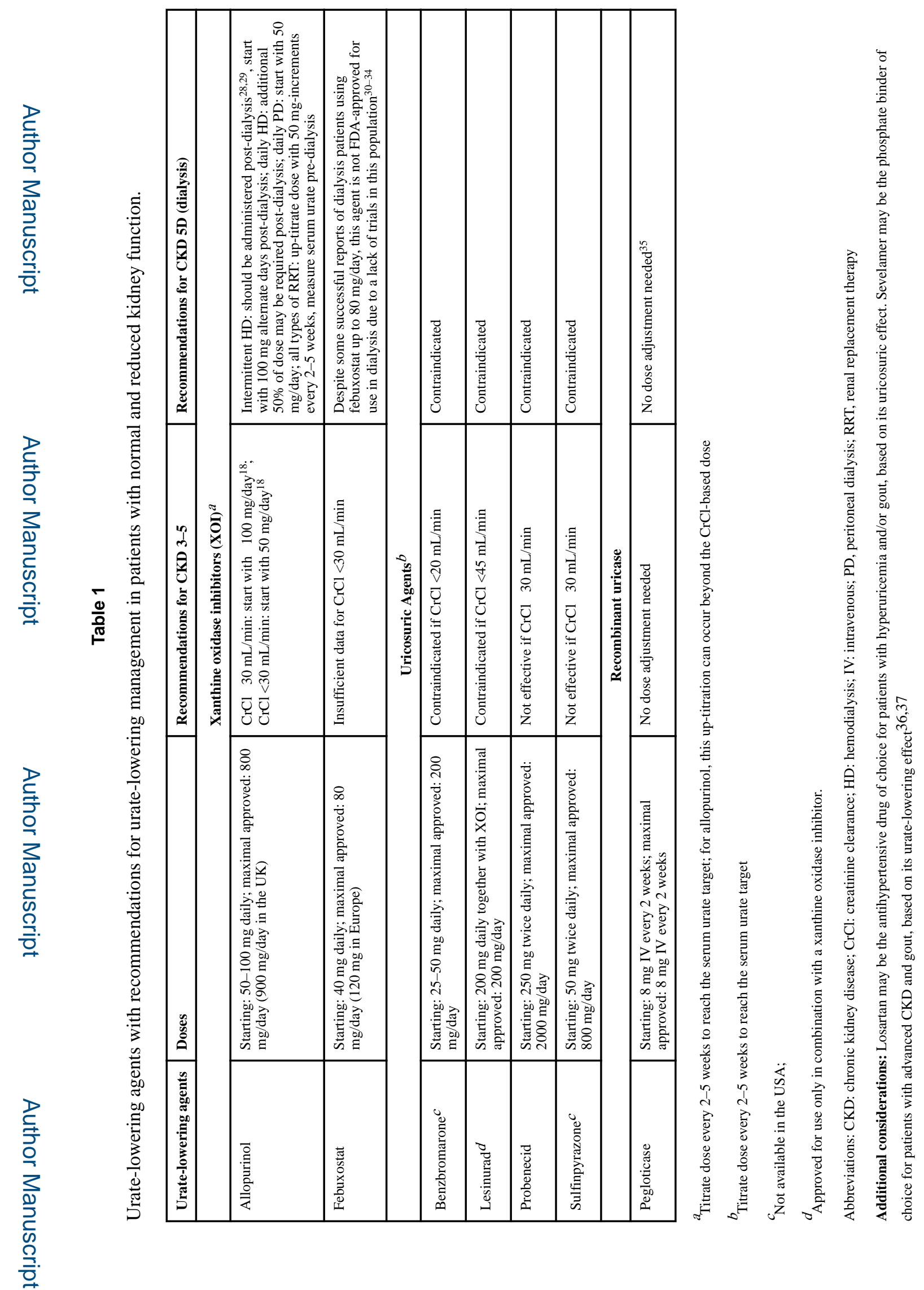

Am J Kidney Dis. Author manuscript; available in PMC 2018 September 01. 


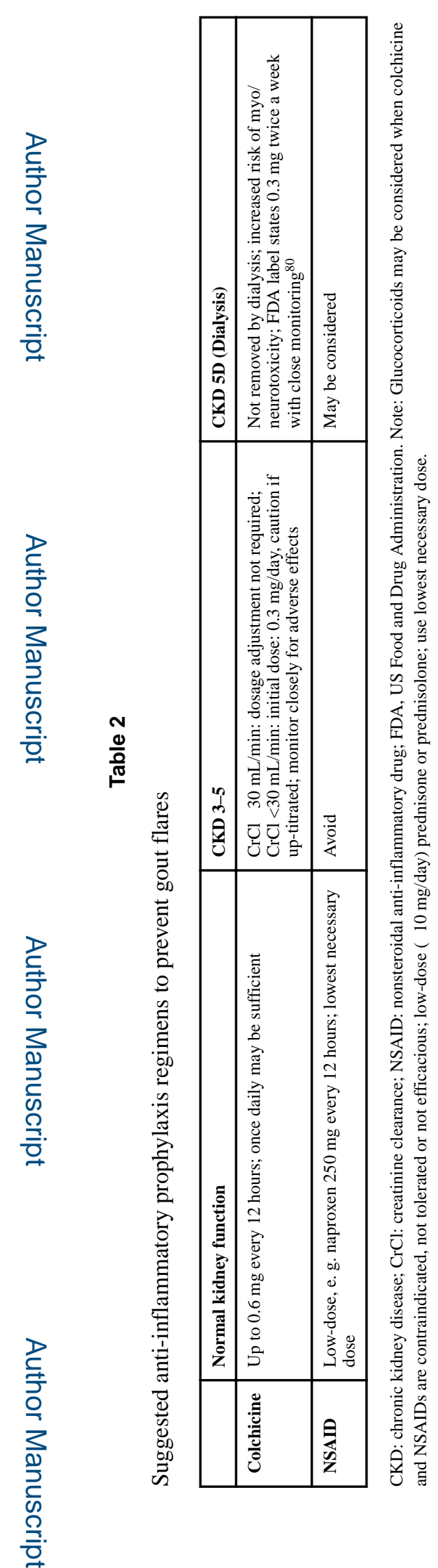

Am J Kidney Dis. Author manuscript; available in PMC 2018 September 01. 


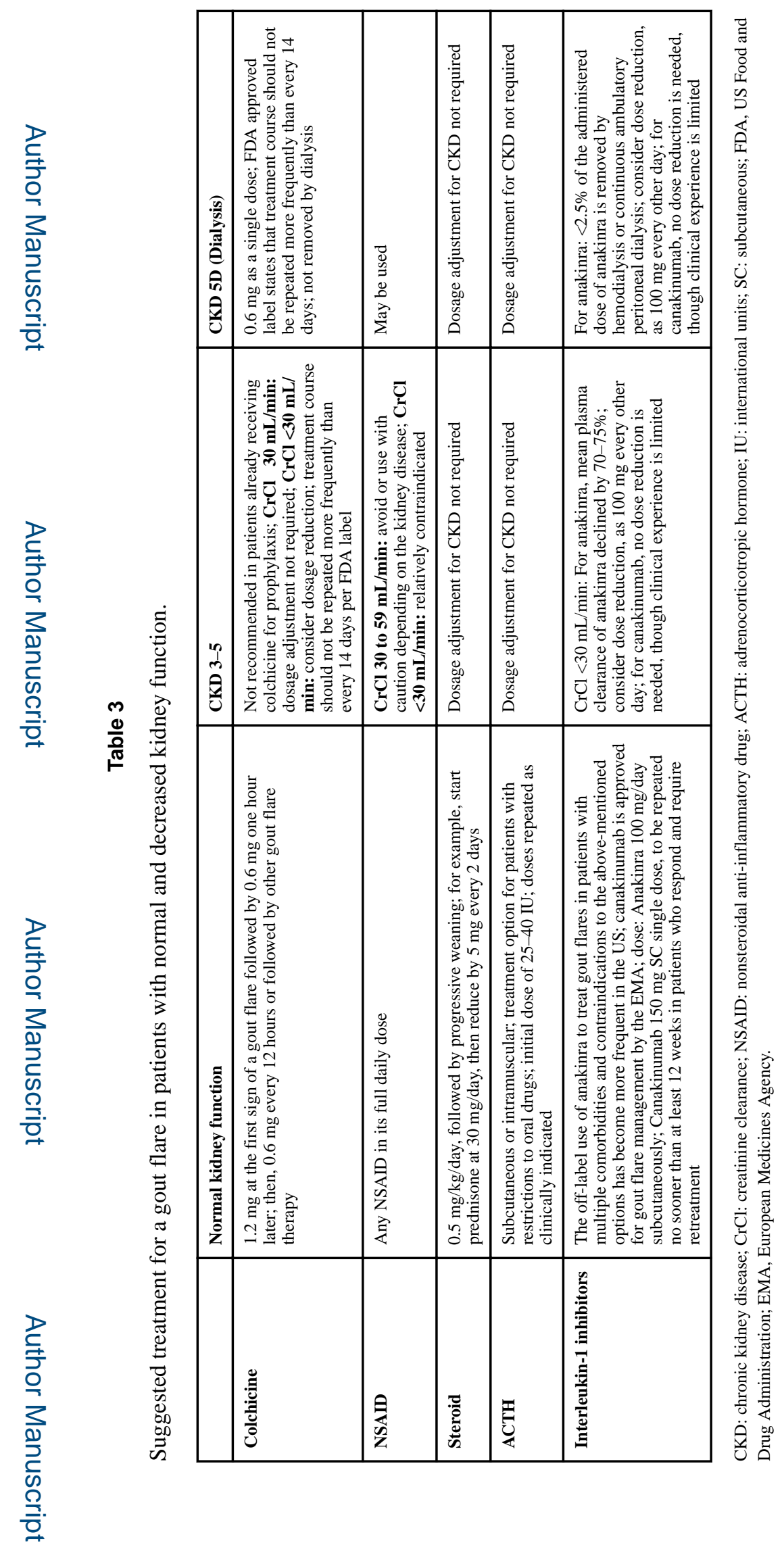

Am J Kidney Dis. Author manuscript; available in PMC 2018 September 01. 


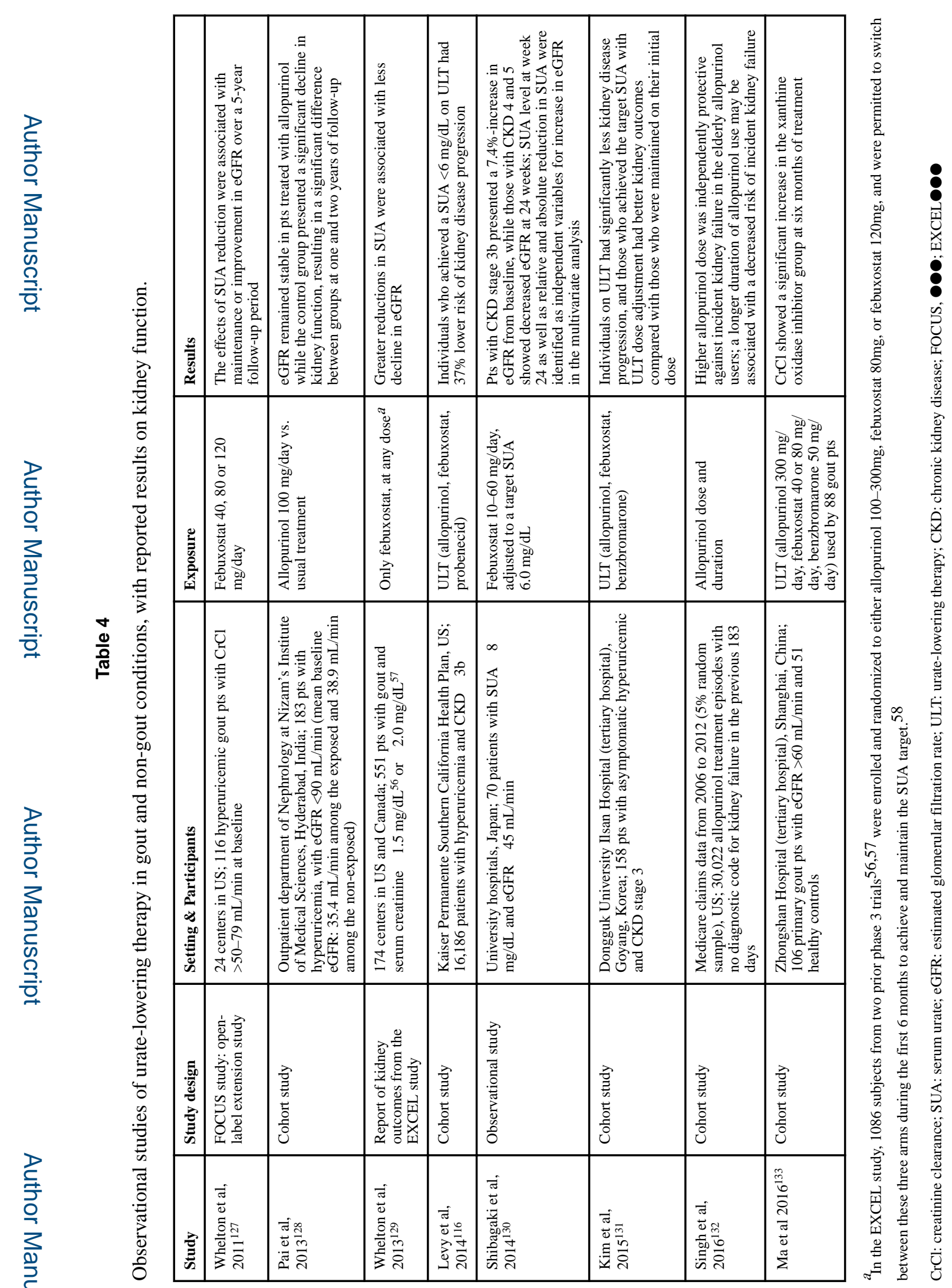

Am J Kidney Dis. Author manuscript; available in PMC 2018 September 01. 


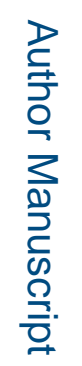

\begin{tabular}{|c|c|c|c|c|c|c|c|c|}
\hline 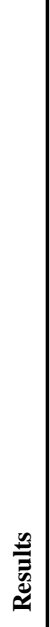 & 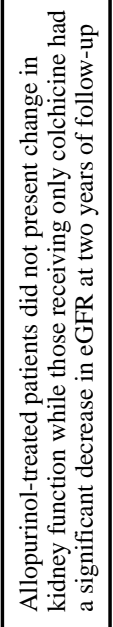 & 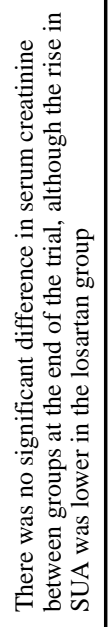 & 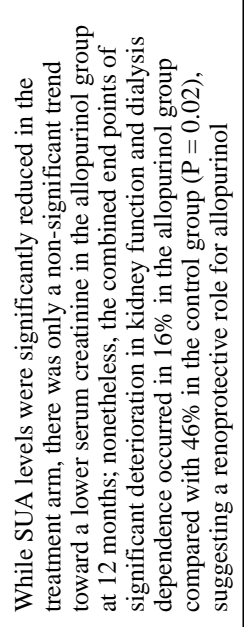 & 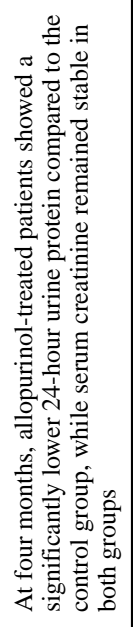 & 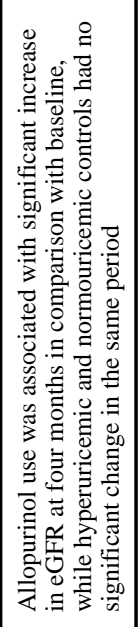 & 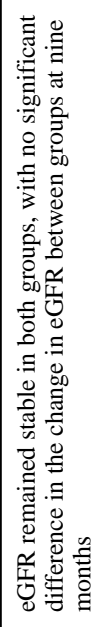 & 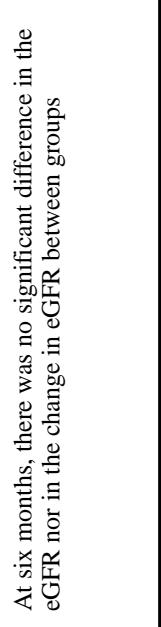 & 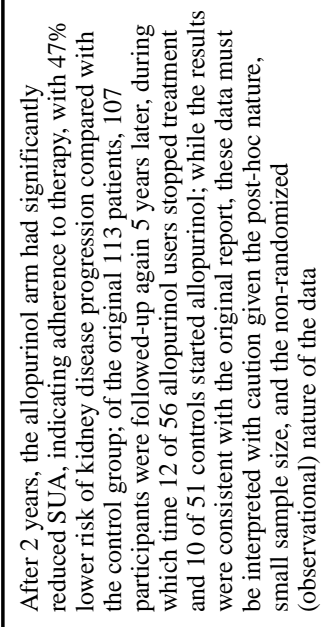 \\
\hline |̃ & 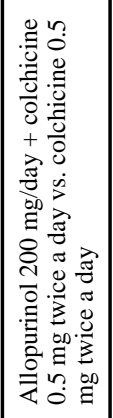 & 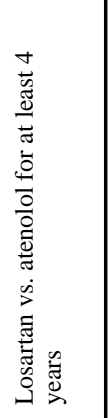 & 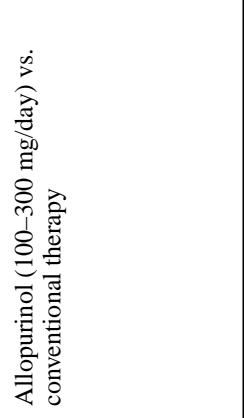 & 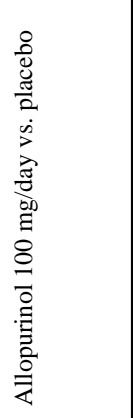 & 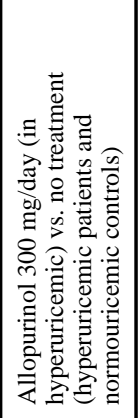 & 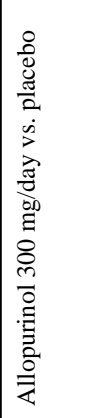 & 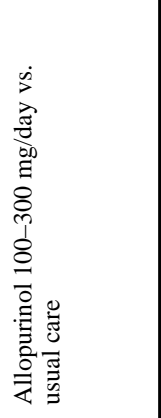 & 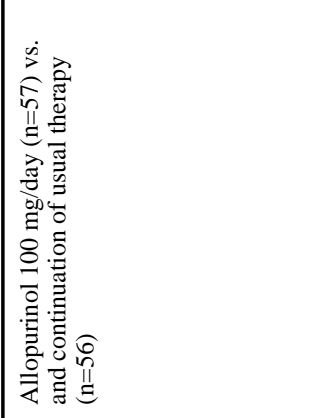 \\
\hline 䔍 & 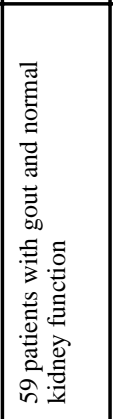 & 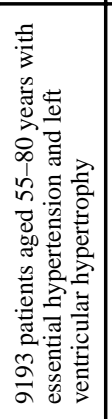 & 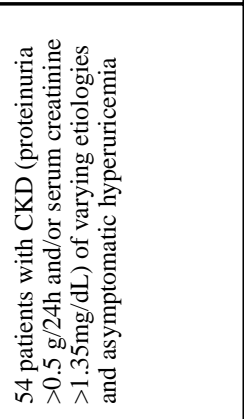 & 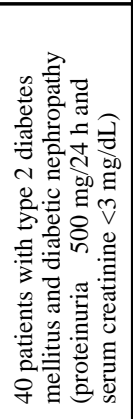 & 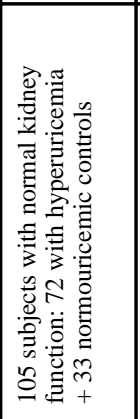 & 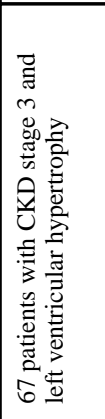 & 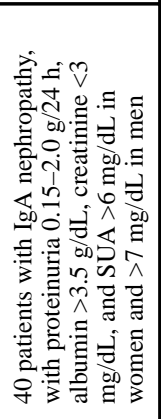 & 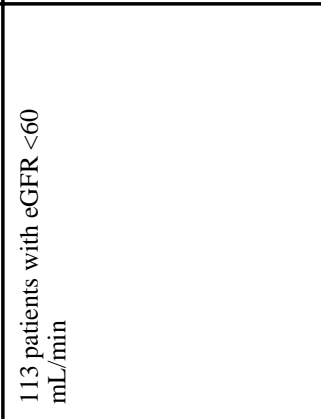 \\
\hline 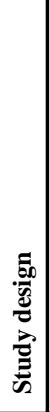 & 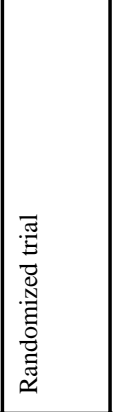 & 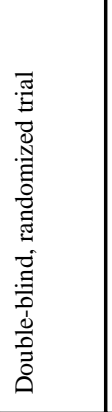 & 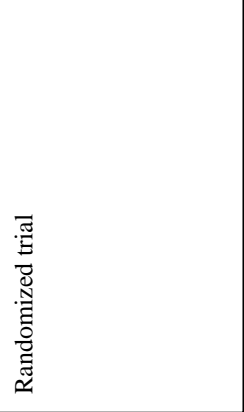 & 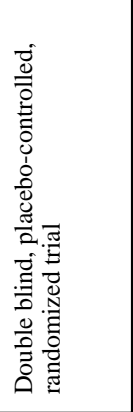 & 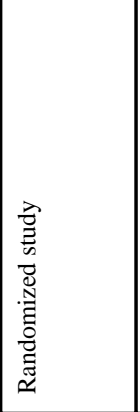 & 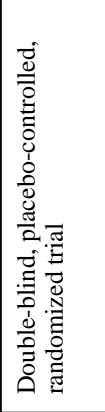 & 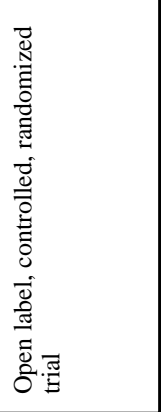 & 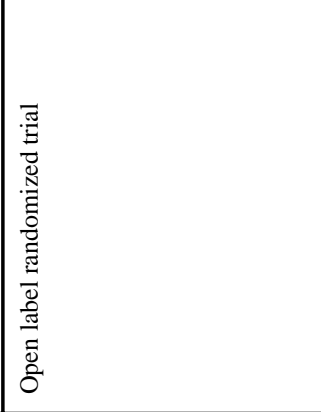 \\
\hline 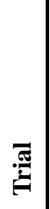 & 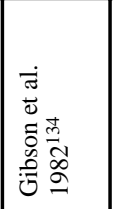 & 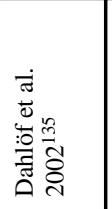 & 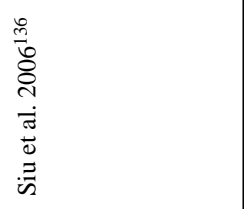 & 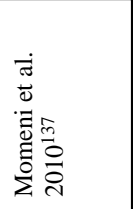 & 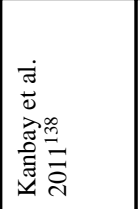 & 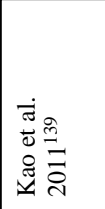 & 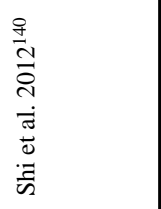 & 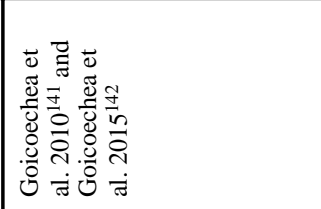 \\
\hline
\end{tabular}

Am J Kidney Dis. Author manuscript; available in PMC 2018 September 01. 


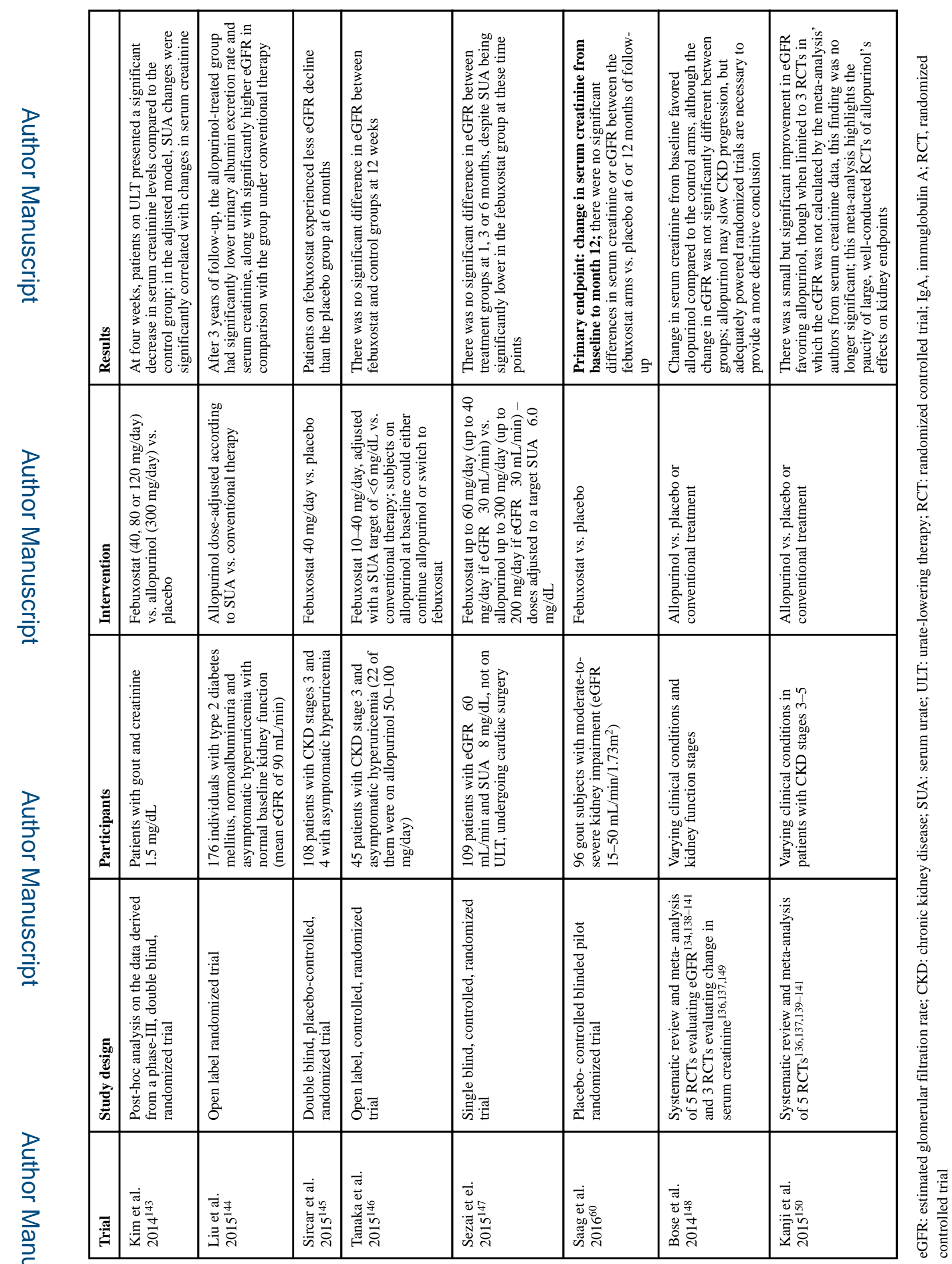

Am J Kidney Dis. Author manuscript; available in PMC 2018 September 01. 